University of Montana

ScholarWorks at University of Montana

Numerical Terradynamic Simulation Group

Publications

Numerical Terradynamic Simulation Group

$12-1991$

\title{
What does Remote Sensing Do for Ecology?
}

J. Roughgarden

Steven W. Running

University of Montana - Missoula

P. A. Matson

Follow this and additional works at: https://scholarworks.umt.edu/ntsg_pubs

Let us know how access to this document benefits you.

\section{Recommended Citation}

Roughgarden, J., Running, S. W. and Matson, P. A. (1991), What Does Remote Sensing Do For Ecology?. Ecology, 72: 1918-1922. doi:10.2307/1941546

This Article is brought to you for free and open access by the Numerical Terradynamic Simulation Group at ScholarWorks at University of Montana. It has been accepted for inclusion in Numerical Terradynamic Simulation Group Publications by an authorized administrator of ScholarWorks at University of Montana. For more information, please contact scholarworks@mso.umt.edu. 


\title{
What Does Remote Sensing Do For Ecology?
}

\author{
J. Roughgarden; S. W. Running; P. A. Matson
}

Ecology, Vol. 72, No. 6 (Dec., 1991), 1918-1922.

Stable URL:

http://links.jstor.org/sici?sici=0012-9658\%28199112\%2972\%3A6\%3C1918\%3AWDRSDF\%3E2.0.CO\%3B2-Y

Your use of the JSTOR archive indicates your acceptance of JSTOR's Terms and Conditions of Use, available at http://www.jstor.org/about/terms.html. JSTOR's Terms and Conditions of Use provides, in part, that unless you have obtained prior permission, you may not download an entire issue of a journal or multiple copies of articles, and you may use content in the JSTOR archive only for your personal, non-commercial use.

Each copy of any part of a JSTOR transmission must contain the same copyright notice that appears on the screen or printed page of such transmission.

Ecology is published by The Ecological Society of America. Please contact the publisher for further permissions regarding the use of this work. Publisher contact information may be obtained at http://www.jstor.org/journals/esa.html.

Ecology

(C)1991 The Ecological Society of America

JSTOR and the JSTOR logo are trademarks of JSTOR, and are Registered in the U.S. Patent and Trademark Office. For more information on JSTOR contact jstor-info@umich.edu.

C2003 JSTOR 


\title{
WHAT DOES REMOTE SENSING DO FOR ECOLOGY?'
}

\author{
J. ROUGHGARDEN \\ Department of Biological Sciences, Stanford University, \\ Stanford, California 94305 USA \\ S. W. RUNNING \\ Department of Forestry, University of Montana, Missoula, Montana 59812 USA \\ P. A. MATSON \\ Ecosystem Science and Technology Branch. NASA-Ames Research Center, \\ Moffett Field, California 94035-1000 USA
}

The phrase "remote sensing" sounds like a theoretician's delight - a way to get data while sitting in an armchair. Unfortunately, while some remote sensing activities can be done in a chair, substantial legwork is also needed to ensure accurate interpretation of remotely sensed signals. Even for the work done from the armchair, remote sensing analysis is far from simple and straightforward.

Nevertheless, remote sensing has a great deal to offer ecologists. In this paper, we will describe some of our own experiences using remote sensing data, provide a brief discussion of some notable successes by other ecologists, and offer our thoughts on some of the impediments to the use of remote sensing by ecologists. This paper is not meant to provide a thorough review of remote sensing in biology; for that, we recommend the papers and books listed at the beginning of the next section.

For the purposes of this paper we define remote sensing as the measurement of reflected, emitted, or backscattered electromagnetic radiation from Earth's surface using instruments stationed at a distance from the site of interest. Most of the instruments utilized are mounted on airborne or spaceborne platforms, although hand-held and tower-based instruments can also be used.

The promise remote sensing technology offers to ecology is to provide data at large and synoptic scales. These are the scales about which we have had to deduce properties based on measurements taken at finer scales. Now, with remote sensing technologies, we can hope to directly discern large-scale patterns in ecological systems, and to measure large-scale processes as they take

' For reprints of this Special Feature, see footnote 1, page 1917. place. Moreover, we have access to longer term, more continuous data over much wider regions than has previously been practical with ground-based monitoring.

\section{Remote Sensing for ECOlOGical PURPOSES}

A number of recent reviews, special issues, book chapters, and entire books have discussed the current and potential uses of remote sensing for biological studies (see Robinson 1985, Greegor 1986, Asrar 1989, Wickland 1989, Graetz 1990, Hobbs and Mooney 1990 , Wickland $1991 a$, for a few examples). These documents describe the use of remote sensing for classification of land surface cover, detection of vegetation phenology, frequency and extent of fire, inundation extent, surface soil moisture in areas of low vegetation cover, land and ocean surface temperature and vegetation stress, and calculation of various ocean color indices and vegetation indices. For these uses, remote sensing tools and approaches are pretty well proven, at least under specific conditions. There is a whole other suite of ecological information for which remote sensing tools are only now being planned, developed, or tested. These include estimates of global net primary production, rates of evapotranspiration, canopy structural characteristics, canopy biochemical constituents, and vegetation water content (see Ustin et al. 1991, part of this Special Feature, for a discussion of some of these). These are hopes for the future, but they are certainly not sure things, and they are in no way ready for immediate application.

Despite the fact that there are a number of remote sensing tools demonstrably ready for use, surprisingly few ecologists have actually used them. The literature is full of papers that demonstrate the potential for use 
of remote sensing data in biological studies; there are also many examples of application of remote sensing data in agriculture, forest, and rangeland management. The studies in which remote sensing data has actually been used to address specific ecological questions or hypotheses, however, are limited.

In the following paragraphs, we describe several ecological studies that have employed remote sensing in hypothesis development and testing. As noted earlier, our purpose is not to present a complete review of all remote sensing studies related to biology or ecology, but to offer a few examples of the ways in which we and others have used remote sensing data.

\section{The recruitment problem in marine population dynamics}

The central problem in marine population dynamics is to account for notoriously large fluctuations in abundance. Most coastal marine animal species have a twophase life cycle, wherein the adults (the "stock") are localized to a benthic habitat, while the larvae live for weeks to months in the offshore waters. The fluctuations in abundance of the stocks is caused in large part by the arrival of pulses of larvae ("recruitment" pulses). Recruitment pulses become discrete cohorts, revealed as bulges in a histogram of the body sizes in the stock. The so-called recruitment problem is to explain (1) why the recruits arrive in discrete pulses, rather than as some more or less continuous trickle, and (2) the timing of the pulses.

The recruitment problem may be nearly solved for intertidal barnacle populations in central California, and remote sensing techniques have contributed greatly to the present understanding. Recruitment pulses seem to result from the collision of upwelling fronts with the rocky intertidal zone. During the upwelling season in the spring and early summer, when the barnacles are reproductive, a front develops between cold and salty water that is upwelled adjacent to the coast and the relatively warm and less salty water offshore, characteristic of the California Current that flows toward the Equator. The front is a place of convergence, because water at the sea surface flows to it from both directions, and larvae, drift algae, and debris accumulate there. The location of this front depends on the strength of upwelling, which in turn depends on the strength of alongshore winds. When the winds relax sufficiently, coastal upwelling shuts down, and the front migrates toward shore. Eventually, the front collides with the shore, depositing the larvae accumulated in it. The arriving larvae produce a recruitment pulse that then reverberates throughout the benthic community. The motion of this front is like a "tattered curtain" that billows in and out before an open window. This hypothesis offers a mechanism to explain both why larvae are concentrated into discrete pulses, and when the pulses arrive at the adult stock (Roughgarden et al. 1988, Farrell et al. 1990, Roughgarden et al. 1991).

Developing and testing the tattered-curtain hypothesis for barnacle recruitment has involved coordinated efforts in rocky intertidal habitat sampling, offshore sampling in the California Current, and remote sensing analysis. Although radar measurements of surface water currents are now being carried out, the key remote sensing information to date is a time sequence of sea surface temperatures from the Advanced Very High Resolution Radiometer (AVHRR) on the NOAA satellites. The offshore-moving water upwelled adjacent to the coast is colder than the southward-flowing water offshore. (The upwelled water is also more saline, but this characteristic is not sensed by the satellite.) By inspecting the temperature data from the AVHRR, the intensity of the upwelling can be assayed, and the position of the fronts can be determined. This information is then used in combination with ground-based sampling to predict both the timing and spatial distribution of recruitment pulses. Clearly, the use of AVHRR data to locate upwelling is not new; it is even being used by commercial fishermen who work with images faxed to them while at sea. What is new is a theoretical ecologist's use of the data to understand coarse-scale population dynamics.

\section{Regional analysis of terrestrial ecosystems}

The primary reason that there is still controversy over whether terrestrial vegetation is a source or a sink of $\mathrm{CO}_{2}$ in the global carbon cycle (Tans et al. 1990) is that we are unable to quantify seasonal $\mathrm{CO}_{2}$ balances over large areas. Further, although we know that the atmosphere influences vegetation, we do not know how vegetation feeds back to influence climate, regionally and ultimately globally (Shukla et al. 1990). How can we quantify these effects and the effects of drought, air pollution, and land-use changes on vegetation and ecosystems at regional scales? These problems and many more require accurate quantitative analysis of regional ecosystem activity. Unfortunately, the knowledge we have acquired and the measurement techniques that we use on typical 0.1 -ha plots, while valuable, may not provide answers at coarser spatial scales.

Two of the most important tools for extrapolating ecological understanding from local to regional scales are remote sensing and computer simulation modeling, two very synergistic technologies. Only a handful of the variables that terrestrial ecologists are interested in will ever be directly observable with optical satellite sensors. Most gas exchange processes such as photosynthesis, respiration, evapotranspiration, and deni- 
trification, and soil processes such as decomposition and mineralization, cannot be detected by optical sensors. However, process-level simulation models that calculate the cycling of carbon, nitrogen, and water through terrestrial ecosystems can simulate these invisible processes and are progressively being validated. While many of the earlier and current models require ground-based information (e.g., stem diameter) as driving variables, some recent efforts have been directed toward development of models that can utilize remote sensing data as input variables.

One such model, the FOREST-BGC model (Running and Coughlan 1988), computes hydrologic and canopy gas-exchange processes in daily time steps, and carbon and nitrogen cycle processes in seasonal or yearly time steps. The model requires daily meteorologic data as well as canopy leaf area indices (LAI) as driving variables. Leaf area index has been used for decades as a means of quantifying canopy structure and scaling canopy process rates. In this case, it is an especially important driving variable because it can be estimated using Landsat Thematic Mapper and AVHRR sensors (Running et al. 1986, Peterson et al. 1987, Spanner et al. 1990).

Combining a few key observable parameters derived from satellite data with an ecosystem simulation model specifically designed to use satellite information allows regional-scale calculations of canopy process rates. FOREST-BGC was a conscious attempt to describe forest ecosystem processes with minimal complexity, and to use satellite and climatological data as input variables. Mapping of annual evapotranspiration and net photosynthesis of a $1200 \mathrm{~km}^{2}$ area of Montana coniferous forests was accomplished using this combination of data and model (Running et al. 1987, Nemani and Running 1989, Running et al. 1989), and is allowing us to test hypotheses about landscape-level patterns in ecological processes.

Modelled estimates of such processes as photosynthesis and respiration are difficult to validate on regional and continental scales. As more simulation ecological models and remote sensing algorithms become available, it may be possible to compare outputs of various models, in a sense testing models against each other. For example, we explored, by computer simulation, whether simulated annual photosynthesis, transpiration, and net primary production were correlated with the annual time-integrated Normalized Difference Vegetation Index (NDVI), a commonly used index of vegetation activity derived from satellite data (Justice et al. 1985, Tucker et al. 1985a, b. Goward et al. 1986). The high correlations found between these variables give some confidence that continental-scale NDVI maps represent vegetation activity reasonably well (Running and Nemani 1988). Likewise, Burke et al. (1990) used seasonal AVHRR NDVI to compare to and validate simulations of annual grassland net primary productivity for the Great Plains.

\section{Other examples}

One of the most obvious yet difficult uses of remote sensing in ecology is in monitoring change: successional change, land use change, deforestation, environmental change, and so on (Hobbs 1990, Pickup 1990). A number of studies have employed remote sensing to analyze rates and patterns in deforestation in the tropics and elsewhere (Woodwell et al. 1984, Malingreau and Tucker 1988, Sader and Joyce 1988). Such information has been useful in understanding causes of deforestation and the impact of tropical deforestation on carbon cycling (Woodwell et al. 1984) and trace gas emissions (Matson et al. 1990). Other studies have used remote sensing to detect changing successional patterns (Hall et al. 1991) and changing patterns in phenology and production in response to regional drought (Tucker et al. 1985a). Monitoring of change is obviously one of the most important contributions of remote sensing technology to studies of global ecological change, and is heralded as such in many of the United States and international global change documents (Earth System Sciences Committee 1988, National Research Council 1988, Committee on Earth Sciences 1990).

Understanding the relative importance of environmental and edaphic variables on vegetation distribution and biological processes has been a topic of interest in ecology for decades. Smith et al. (1990) recently applied a remote sensing approach to examine the effects of radiation, temperature, elevation, soil type, and precipitation on vegetation in desert scrub areas; on a regional scale, they found desert scrub to be most influenced by mean annual precipitation. Their work also demonstrated that conclusions derived from local-scale relationships could not be extrapolated safely to the regional scale, and that a combination of local field measurements and regional remote sensing measurements were required to determine the environmental controls on vegetation.

As a final example, remote sensing data has also been used in hypothesis testing at global scales. Fung et al. (1987) used the NDVI derived from the AVHRR, together with measurements of soil respiration and climate data, to determine geographic distributions of monthly $\mathrm{CO}_{2}$ exchange between biosphere and atmosphere. Those estimates were compared with estimates simulated from a three-dimensional atmospheric tracer model that combined $\mathrm{CO}_{2}$ data from a ground sampling network with a general circulation model. Their results indicated good correspondence between the duration of high NDVI and the duration of $\mathrm{CO}_{2}$ drawdown indicated by the tracer model. 


\section{IMPEDIMENTS TO THE USE OF REMOTE} SENSING DATA IN ECOLOGY

In all of these examples, remote sensing has been used for detection of characteristics of interest in ecology, either to formulate or test hypotheses, or to aid in estimates of ecological processes on regional and global scales. This is not an exhaustive list, but there are not many more examples. At first glance, it seems strange that ecologists have failed to take better advantage of this tool, as they have taken advantage of other new tools such as isotope analysis and modelling. There are, however, a number of reasons why remote sensing technology has not made strong inroads in ecology yet, although these constraints are rapidly eroding.

First, satellite remote sensing data are expensive; the privatized Landsat Thematic Mapper data cost $\$ 3900$ / scene, Landsat Multi Spectral Scanner data cost $\$ 1000 /$ scene, and French SPOT data is $\$ 1800 /$ scene, although educational discounts of $\$ 600 /$ scene are currently being offered. However, the United States Geological Survey EROS Data Center in South Dakota is finalizing a system to produce biweekly composited five-channel and NDVI AVHRR datasets of the United States for 1990 and North America for 1991. The 1990 datasets are available on five CD-ROMs (each with 800 Mbytes of data) for $\$ 32$ each. Some satellite data is becoming available, effectively free, from centralized databanks accessible over high-speed computer networks.

Second, communication gaps have existed between scientists who specialize in remote sensing and those who study ecology. Ecologists rarely are educated in image analysis or biophysics, and many lack the background in mathematics and statistics required for remote sensing analysis. Thus, it is difficult for many ecologists simply to give remote sensing a try; instead, they hire appropriate personnel usually trained in physical science disciplines, who typically do not know ecology. In this interdisciplinary era, however, it is likely that the next generation of ecologists will have coursework in remote sensing and digital image processing.

Third, in the past, very few of the remote sensing scientists who build and deploy instruments have been ecologists. Moreover, there has never been a remote sensing instrument designed primarily for ecological research (Wickland 1991a), so we frequently end up using instruments that are not optimized for our field applications, nor adequately calibrated for ecological uses. Some of the instruments planned for the Earth Observing System (see Wickland $1991 b$ and Ustin et al. 1991 in this Special Feature) will help to remedy this situation.

Fourth, as recently as $10 \mathrm{yr}$ ago, the computer hardware and software needed to work with satellite data required a million dollar mainframe computer and dedicated staff to run the image-processing software. Thanks to the microcomputer revolution, an investment of as little as $\$ 800$ for a commercial image-processing software package, or $\$ 0$ for public domain software such as the Utah Raster Toolkit available over Internet, plus an IBM compatible 80286 PC with EGA monitor, can now get one into remote sensing! One of us (S. W. Running) has put an image-processing system on a laptop computer, and has done single-channel image processing in the field, while looking at the terrain of interest. Image analysis is readily carried out using $\mathrm{X}$-windows on UNIX workstations. These advances in affordable technology bring remote sensing closer to ecologists.

Finally, it may be that ecologists only recently have become interested in processes and patterns occurring at scales amenable to remote sensing. There is a growing need to understand ecological relationships in the context of a changing world (Lubchenco et al. 1991); we hope that remote sensing will provide one pathway for study of ecological patterns and processes in the midst of change. With public interest and funding levels increasing in the area of global and environmental change, and with the awareness that remote sensing observations are a critical component of global research, more and more opportunities exist for ecologists (including graduate students and post-doctoral scientists) to contribute to the planning of future sensors and to use currently available sensors.

\section{ACKNOWLEDGMENTS}

We thank J. Franklin, S. Ustin, and P. Vitousek, and several anonymous reviewers, who commented on earlier drafts of this manuscript, and Chris Zupanovich, who prepared several drafts of the manuscript.

\section{LITERATURE CITED}

Asrar, G., editor. 1989. Theory and applications of optical remote sensing. John Wiley \& Sons, New York, New York, USA.

Burke, I. C., D. S. Schimel, C. M. Yonker, W. J. Parton, L. A. Joyce, and W. K. Lauenroth. 1990. Regional modeling of grassland biogeochemistry using GIS. Landscape Ecology 4:45-54.

Committee on Earth Sciences. 1990. Our changing planet: the FY 1991 research plan. United States Global Change Research Program. Office of Science and Technology Policy, Washington, D.C., USA.

Earth System Sciences Committee. 1988. Earth system science: a closer view. A program for global change. National Aeronautics and Space Administration Advisory Council, Washington, D.C., USA.

Farrell, T. M., D. Bracher, and J. Roughgarden. 1990. Crossshelf transport causes recruitment to intertidal populations in Central California. Limnology and Oceanography, in press.

Fung, I. Y., C. J. Tucker, and K. C. Prentice. 1987. Application of advanced very high resolution radiometer vegetation index to study atmosphere-biosphere exchange of $\mathrm{CO}_{2}$. Journal of Geophysical Research 92(D3):2999-3015. 
Goward, S. N., C. J. Tucker, and D. G. Nye. 1986. North American vegetation patterns observed with the NOAA-7 Advanced Very High Resolution Radiometer. Vegetatio 64: 3-14.

Graetz, R. D. 1990. Remote sensing of terrestrial ecosystem structure: an ecologist's pragmatic view. Pages 5-30 in R. J. Hobbs and H. A. Mooney, editors. Remote sensing of biosphere functioning. Springer-Verlag, New York, New York, USA.

Greegor, D. H., Jr. 1986. Ecology from space. BioScience $36: 429-432$.

Hall, F. G., D. B. Botkin, D. E. Strebel, K. D. Woods, and S. J. Goetz. 1991. Large-scale patterns of forest succession as determined by remote sensing. Ecology 72:628-640.

Hobbs, R. J. 1990. Remote sensing of spatial and temporal dynamics of vegetation. Pages 203-220 in R. J. Hobbs and H. A. Mooney, editors. Remote sensing of biosphere functioning. Springer-Verlag, New York, New York, USA.

Hobbs, R. J., and H. A. Mooney, editors. 1990. Remote sensing of biosphere functioning. Springer-Verlag, New York, New York, USA.

Justice, C. O., J. R. G. Townshend, B. N. Holben, and C. J. Tucker. 1985. Analysis of the phenology of global vegetation using meteorological satellite data. International Journal of Remote Sensing 6:1271-1318.

Lubchenco, J., A. M. Olson, L. B. Brubaker, S. R. Carpenter, M. M. Holland, S. P. Hubbell, S. A. Levin, J. A. MacMahon, P. A. Matson, J. M. Melillo, H. A. Mooney, C. H. Peterson, H. R. Pulliam, L. A. Real, P. J. Regal, and P. G. Risser. 1991. The Sustainable Biosphere Initiative: an ecological research agenda. Ecology 72:371-412.

Malingreau, J. P., and C. J. Tucker. 1988. Large-scale deforestation in the southeastern Amazon Basin of Brazil. Ambio 17:49-55.

Matson, P. A., P. M. Vitousek, G. P. Livingston, and N. A. Swanberg. 1990. Sources of variation in nitrous oxide flux from Amazonian ecosystems. Journal of Geophysical Research 95(D10): 16,789-16,798.

National Research Council. 1988. Toward an understanding of global change. Initial priorities for United States contributions to the International Geosphere-Biosphere Program (IGBP). National Academy Press, Washington, D.C., USA

Nemani, R., and S. W. Running. 1989. Estimation of regional surface resistance to evapotranspiration from NDVI and thermal-IR AVHRR data. Journal of Applied Meteorology 28:276-284.

Peterson, D. L., M. A. Spanner, S. W. Running, and K. B. Teuber. 1987. Relationship of thematic mapper simulator data to leaf area index of temperate coniferous forests. Remote Sensing of the Environment 22:323-341.

Pickup, G. 1990. Remote sensing of landscape processes. Pages 221-247 in R. J. Hobbs and H. A. Mooney, editors. Remote sensing of biosphere functioning. Springer-Verlag, New York, New York, USA

Robinson, I. S. 198j. Satellite oceanography. Ellis Horwood, Chichester, England.

Roughgarden, J., S. Gaines, and H. Possingham. 1988. Recruitment dynamics in complex life cycles. Science $\mathbf{2 4 1}$ : $1460-1466$.

Roughgarden, J., J. T. Pennington, D. Stoner, S. Alexander, and K. Miller. 1991. Collisions of upwelling fronts with the intertidal zone: the cause of recruitment pulses in barnacle populations of central California. Acta Oecologica 12 in press.
Running, S. W., and J. C. Coughlan. 1988. A general model of forest ecosystem processes for regional applications. Ecological Modelling 42:125-154.

Running, S. W., and R. R. Nemani. 1988. Relating seasonal patterns of the AVHRR vegetation index to simulated photosynthesis and transpiration of forests in different climates. Remote Sensing of Environment 24:347-367.

Running, S. W., R. R. Nemani, and R. D. Hungerford. 1987. Extrapolation of synoptic meteorological data in mountainous terrain, and its use for simulating forest evapotranspiration and photosynthesis. Canadian Journal of Forest Research 17:472-483.

Running, S. W., R. R. Nemani, D. L. Peterson, L. E. Band, D. F. Potts, L. L. Pierce, and M. A. Spanner. 1989. Mapping regional forest evapotranspiration and photosynthesis by coupling satellite data with ecosystem simulation. Ecology 70:1090-1101.

Running, S. W., D. L. Peterson, M. A. Spanner, and K. B. Tueber. 1986. Remote sensing of coniferous forest leaf area. Ecology 67:273-276.

Sader, S. A., and A. T. Joyce. 1988. Deforestation rates and trends in Costa Rica, 1940-1983. Biotropica 20:11-19.

Shukla, J., C. Nobre, and P. J. Sellers. 1990. Amazon deforestation and climate change. Science 247:1322-1325.

Smith, M. O., S. L. Ustin, J. B. Adams, and A. R. Gillespie. 1990. Vegetation in deserts: II. Environmental influences on regional abundance. Remote Sensing of Environment 29:27-52.

Spanner, M. A., L. L. Pierce, S. W. Running, and D. L. Peterson. 1990. The seasonality of AVHRR data of temperate coniferous forests: relationship to leaf area index. Remote Sensing of Environment 33:97-112.

Tans, P. P., I. Y. Fung, and T. Takahashi. 1990. Observational constraints on the global atmospheric $\mathrm{CO}_{2}$ budget. Science 247:1431-1438.

Tucker, C. J., J. R. G. Townshend, and T. E. Goff. $1985 b$. African land cover classification using satellite data. Science 227:369-375.

Tucker, C. J., C. L. Vanpraet, M. J. Sharman, and G. van Ittersum, 1985a. Satellite remote sensing of total herbaceous biomass production in the Senegalese Sahel: 19801984. Remote Sensing of Environment 17:233-249.

Ustin, S. L., C. A. Wessman, B. Curtiss, E. Kasischke, J. Way, and V.C. Vanderbilt. 1991. Opportunities for using the EOS imaging spectrometers and synthetic aperture radar in ecological models. Ecology 72:1934-1945.

Wickland, D. E. 1989 . Future directions for remote sensing in terrestrial ecological research. Pages 691-724 in G. Asrar, editor. Theory and applications of optical remote sensing. John Wiley \& Sons, New York, New York, USA.

- 1991a. Global ecology: the role of remote sensing. In G. Esser and D. Overdieck, editors. Facets of modern ecology. Elsevier, Amsterdam, The Netherlands, in press.

$1991 b$. Mission to Planet Earth: the ecological perspective. Ecology 72:1923-1933.

Woodwell, G. M., J. E. Hobbie, R. A. Houghton, J. M. Melillo, B. Moore, A. B. Park, B. J. Peterson, and G. R. Shaver. 1984. Measurement of changes in the vegetation of the earth by satellite imagery. Pages 221-240 in G. M. Woodwell, editor. The role of terrestrial vegetation in the global carbon cycle. Scope 23. John Wiley \& Sons, New York, New York, USA 